Tropical Journal of Pharmaceutical Research August 2012; 11 (4): 683-689

(c) Pharmacotherapy Group, Faculty of Pharmacy, University of Benin

Benin City, 300001 Nigeria.

All rights reserved.

\title{
A Study of the Prevalence of Self-Medication Practice among University Students in Southwestern Nigeria
}

\author{
KP Osemene and A Lamikanra
}

Faculty of Pharmacy, Obafemi Awolowo University, Ile-Ife, Osun State, Nigeria.

\begin{abstract}
Purpose: To estimate the prevalence of self-medication with antibiotics and antimalarials among university students in southwestern Nigeria and evaluate the factors associated with self-medication.

Methods: A pre-tested questionnaire was used to collect data from 2000 university students using a convenient sampling technique. Prevalence of the practice of self-medication was estimated in percentages while factors associated with self-medication were evaluated using multiple regression analysis.

Results: The prevalence of the practice of self-medication was high among the age group of $25-44$ years but lower in the $15-24$ and $\geq 45$ year age groups, respectively. Females exhibited higher prevalence of self-medication than males. Among undergraduates, self-medication increased as the students' class level in the university increased. Postgraduate students exhibited low prevalence of selfmedication practices. Self-medication was significantly associated with age, gender and students' class level in the university at $p^{\prime}<0.001$. A majority, $982(53.8 \%)$, of the students used antibiotics for selfmedication while $845(46.3 \%)$ used anti-malarial drugs for self-medication. Sources of drugs for selfmedication were patent medicines store (901 or $49.3 \%$ ), community pharmacies (531 or $29.1 \%$ ), friends (210 or $11.5 \%$ ), relatives (130 or $7.1 \%$ ) and left-over drugs from previous prescriptions (55 or $3.0 \%)$.

Conclusion: The study revealed that age, gender and students' level in the university influenced selfmedication practices. The use of antibiotics in self-medication calls for urgent health policy intervention.
\end{abstract}

Keywords: Self-medication, Antimalarial, Antibiotics, University students, Nigeria. 


\section{INTRODUCTION}

Self-medication is the use of drugs with therapeutic intent but without professional advice or prescription. It has also been defined as the use of nonprescription medicines by people on their own initiative [1]. Drugs that are prone to self-medication include analgesics, antimalarials, antibiotics and cough syrups, among others [2]. Self-medication with antibiotics occur in many developing countries where drugs are not well-regulated. Hence there is easier access to prescription or over-the-counter medicines without prescription. Self-medication, could cause bacteria resistance to such antibiotics and may precipitate the emergence of multipleresistant organisms that would be difficult to treat and this has caused increased morbidity [3-6]. Perception of illness and incessant advertising, among others, have increased the prevalence of self-medication which accounts for about $2.9-3.7 \%$ causes of death in hospitals as a result of drug-drug interactions [7-13]. It has also been reported that drug use is influenced by the sociodemographic characteristics of drug consumers such as gender, morbidity, age, attitudes about life and health, stress, and social roles but has nothing to do with education and ethnicity [14-16]. Some of the problems associated with self-medication such as masked diagnoses, use of excessive drug dosage, prolonged duration of use, drug interactions, polypharmacy and superinfection can occur in self-medicating individuals .However, there is substantial variation in the prevalence rates of selfmedication among developing and developed nations due to inherent differences in cultural and socioeconomic factors, disparities in health care systems such as reimbursement policies, access to health care, and drug dispensing policies [17].

The prevalence of the practice of selfmedication among university students in southwestern Nigeria has not been widely studied. The factors that influence self- medication practices remain issues of intense debate in academic discourse. Practices in self-medication have raised a lot of unresolved research questions such as: Which ailments do university students treat through self-medication? What are the types and sources of these non-prescribed medicines? Is there any relationship between level of education and self-medication practice? What factors influence selfmedication practices among university students? What strategies can be crafted to discourage self-medication practices in general? The objective of this study was to assess the prevalence of self-medication with antibiotics and antimalarials among university students in southwestern Nigeria, as well as the factors associated with self-medication.

\section{EXPERIMENTAL}

\section{Setting}

Presently, there are a total of 31 private and public universities in South-Western Nigeria. Out of this, only 10 run both undergraduate and postgraduate programmes. Others run undergraduate programmes only [18].

\section{Sample}

A total of 2015 self-administered questionnaires, based on calculated sample size using Raosoft Sample Size Calculator, were distributed to students in the universities using a convenient sampling technique. This technique involved sampling the opinion of the students who were willing to fill the questionnaire or to be interviewed. Those who were not willing to fill the questionnaire or be interviewed were simply ignored. This technique is quicker to conduct and as the name indicates, more convenient to implement. There is no need for call backs and no need for a sampling frame. However, some of the inherent drawbacks include low represent-tativeness and it is prone to sampling errors. However, what is lost in precision can be gained in economy of time and money [19]. Respondents were briefed 
or given explanations about the purpose of the research by trained research assistants. At first contact with the respondents, verbal consent to participate in the study was sought. The questionnaire was completed in the presence of the research assistants should any respondent require any assistance in filling the questionnaire.

\section{Survey instrument}

The questionnaire was in two parts. The first part contained questions on demographic information of the respondents such as age, gender, class level in the university, etc. The second part contained questions on core issues which dwelt on socio-economic variables such as health seeking behavior, names and sources of drugs used for selfmedication, type of ailment treated through self-medication, factors influencing selfmedication practices and strategies that may help reduce self-medication practices among the respondents. The questionnaire, which consisted of close- and open-ended questions were pre-tested for reliability and validity .The pre-tested questionnaire were used to effect minor corrections and modifications where necessary for easy understanding and filling by respondents. The questionnaire was also backed with an oral interview. Some of the questions asked during the oral interview section were: What is your main reason for indulging in selfmedication? Who diagnosed the ailment that led you to self-medication? Do you think education will help reduce the incidence of self-medication?

\section{Data analysis}

This study adopted the method of analysis employed elsewhere to estimate the prevalence of self-medication with antibiotics and antimalarials in the community of Khartoum State, Sudan [14].

Data obtained from the questionnaire were coded, given sequential numbers and entered into the Statistical Package for Social
Sciences (SPSS), version 13, software. Analysis was carried out using descriptive and inferential statistics at $95 \%$ confidence intervals. Prevalence of self-medication among university students were measured in percentages. Regression analysis was employed to determine the influence of socioeconomic factors on self-medication practices among the university students. Since the resultant outputs were binary variables that described the self-medication status of the university students, logistic regression models were employed to assess the predictors. Only multivariate logistic results obtained at $95 \%$ confidence interval were reported as odd ratio. However, separate regression models were fitted for overall selfmedication status of the university students for various groups of identified drugs [14]. Level of significance was set at $p<0.001$.

\section{RESULTS}

The response rate for administered questionnaire was $99.3 \%$ because only 2000 questionnaire were harvested out of the total of 2015 questionnaire administered to respondents. Fifteen respondents did not properly fill the questionnaire, probably due to inadequate guidance, lack of interest in the study and/or time constraint. Consequently, their questionnaires were not used for the study. In all, a majority of the respondents $1827(91.4 \%)$ were involved in selfmedication practices while $173(8.7 \%)$ stated that they were not. Table 1 shows the association between self-medication and respondents characteristics.

The prevalence of self-medication was generally high among the middle age groups of 25 - 34 and 35 - 44 years. The $15-24$ and $\geq 45$ year's age groups exhibited lower prevalence of self-medication behavior. However, females exhibited higher prevalence of self-medication than their male counterpart. At the undergraduate class levels, the prevalence of self-medication increased marginally from $1 \mathrm{st}$ year to 5th year students.. However, postgraduate (PG) 
Table 1: Association between self-medication and respondents' characteristics

\begin{tabular}{llll}
\hline $\begin{array}{l}\text { Respondents' } \\
\text { characteristics }\end{array}$ & $\begin{array}{l}\text { Self-medication } \\
\text { (n=1827) }\end{array}$ & $\begin{array}{l}\text { No self-medication } \\
\text { (n=173) }\end{array}$ & P-value \\
\hline Age (yr) & $315(17.2 \%)$ & $80(46.2 \%)$ & $<0.001$ \\
$15-24$ & $720(39.4 \%)$ & $55(31.8 \%)$ & \\
$25-34$ & $632(34.6 \%)$ & $30(17.3 \%)$ & \\
$35-44$ & $160(8.8 \%)$ & $8(4.6 \%)$ & \\
$\geq 45$ & & & \\
Gender & $798(43.7 \%)$ & $98(56.7 \%)$ & $<0.001$ \\
Males & $1029(56.3 \%)$ & $75(43.4 \%)$ & \\
Females & & & \\
University class level & $101(58.4 \%)$ & \\
100 & $106(5.8 \%)$ & $60(34.7 \%)$ & \\
200 & $364(19.9 \%)$ & $4(2.3 \%)$ & \\
300 & $360(19.7 \%)$ & $3(1.7 \%)$ & \\
400 & $401(22.0 \%)$ & $3(1.7 \%)$ & \\
500 & $400(21.9 \%)$ & $2(1.2 \%)$ & \\
$>500$ (PG students) & $196(10.7 \%)$ & & \\
\hline
\end{tabular}

students exhibited a lower prevalence of self-medication than other categories of students. Self-medication was significantly associated with age, gender and students' level in the university at $p<0.001$. The general pattern of self-medication with all the groups of drugs examined was similar amongst the respondents with respect to age and to a large extent the respondents' level in the universities.

Majority, 845 (46.3\%), of the respondents indicated that they used antimalarial drugs for self-medication while $982(53.8 \%)$ admitted taking antibiotics for self-medication.

The prominent disease conditions that predisposed respondents to self-medication practices with antibiotics were revealed by the respondents as urinary tract infection 427 $(43.5 \%)$, typhoid fever 48 (4.9\%), dysentery 98(10.0\%), cough and catarrh 67 (6.8\%), diarrhea 100(10.2\%), malaria 54 (5.5\%), sore throat 150 (15.3\%), otitis media 20 (2.0 $\%)$ and pneumonia 18 (1.8\%).

The major sources of the drugs used for selfmedication by the respondents were the patent medicine store $901 \quad(49.3 \%)$, community pharmacies $531(29.1 \%)$, friends $210(11.5 \%)$, relatives $130(7.1 \%)$ and leftover drugs from previous prescriptions 55 $(3.0 \%)$.
Based on the oral interview carried out, a majority (64\%) of the respondents admitted that education may not help reduce the incidence of self-medication as well as its attendant prevalence unless such education is part of an enlightment campaign tailored towards the rational use of drugs or lays emphasis on the consequences of indulging in self-medication behavior. The issue of long waiting queues at clinics or hospitals was also raised by $59 \%$ of the respondents as one of the reasons for seeking self-care in order to meet up with their tight lecture schedule. All the respondents (100\%) admitted that they used self-prescribed drugs to treat their self-diagnosed disorders or ailments based on their own initiative.

The adjusted odd ratio (OR) at $95 \%$ confidence interval $(\mathrm{Cl})$ that quantified the association between the socio-demographic variables of age, gender and students' level in the universities and self-medication with antimalarials and antibiotics is presented in Table 2. The estimates were obtained using multiple logistic regression models. The OR data indicate that self-medication with either antibiotics or antimalarials was significantly associated with age, gender and level of 
Table 2: Association between socio-demographic variables and self-medication (SM) behaviour with antimalarials and antibiotics using adjusted odds ratios (OR) and $95 \% \mathrm{Cl}(\mathrm{n}=2000)$.

\begin{tabular}{lllll}
\hline Variable & $\begin{array}{l}\text { Self-medication with } \\
\text { antimalarials }\end{array}$ & $\mathbf{P}$ & $\begin{array}{l}\text { Self-medication with } \\
\text { antibiotics }\end{array}$ & $\mathbf{P}$ \\
\hline Age (year) & & $<0.001$ & & $<0.001$ \\
$15-24$ & 0.2 & & 0.1 & \\
$25-34$ & 1.2 & 1.6 & \\
$35-44$ & 2.3 & 3.5 & $<0.001$ \\
$\geq 45$ & 3.4 & & 3.7 & \\
Gender & & & & \\
Males & 1.7 & & 2.6 & \\
Females & 3.8 & & 4.2 & \\
& & & \\
University level & & & 0.001 & \\
100 & 0.1 & & 0.0 & \\
200 & 0.8 & & 1.7 & \\
300 & 3.2 & 3.2 & \\
400 & 3.6 & & 3.8 & \\
500 & 3.8 & & 3.0 & \\
$>500$ (PG students) & 3.2 & & & \\
\hline
\end{tabular}

education. Overall, self-medication with any antibiotics or antimalarials was least common in the youngest age group (15 - 24 years) and most common among female students.

\section{DISCUSSION}

Self-medication with antimalarial drugs and antibiotics by university students in southwestern Nigeria was high. This finding is in agreement with a similar study which posited that the commonest groups of medication prone to self-medication include antimalarials and antibiotics [2].

These groups of drugs are prone to misuse because they are readily available, and malaria and microbial infections are common. However, the associated prevalence of using these two groups of drugs for self-medication was high and about the same. For instance, the irrational use of antibiotics and antimalarials in self-medication, without proper diagnosis of the disease leads to increased morbidity among population and to the emergence of multiple resistant strains of the causative organisms which are difficult and costly to treat, especially in immunecompromised individuals [3-6] The high frequency of use of these drugs by the students was expected because they live in a malaria endemic region. The high rate of use of antibiotics is probably linked to the high rate of infections which may be as a result of overcrowding in students' halls of residence. The tendency to indulge in self-medication behavior would be assumed to decrease with increase in age and respondents' class level in the university because with corresponding increases in age and educational status, students ought to be more knowledgeable on rational drug use. However, the findings of this study contradicted this assumption except for final year undergraduate students. Generally, there is a strong association between the socio-demographic variables of age, gender and undergraduate and postgraduate students in the university with regard to the prevalence self-medication with antibiotics and antimalarial drugs. This corroborates the result obtained from the oral interview where $64 \%$ of the respondents posited that increase in educational level of students may not help reduce the incidence of self-medication and its attendant prevalence. This may be attributed to some extraneous factors such as advertisement or peer group influence, poverty or financial 
constraints, weak regulation of medicines which facilitates easy access to drugs, long waiting queues at clinics or hospitals, among others $[2,7,8,14]$.

The major source of drugs used for selfmedication by the respondents was patent medicine stores. This finding exposes a loophole in the enforcement of Nigeria's laws on dispensing of medicines as the laws permit patent medicine stores to sell overthe-counter (OTC) medications, of which antibiotics are not. Also, patent medicine proprietors may not have the requisite professional knowledge required to render quality health services to patients in terms of counseling and pharmaceutical care. In addition to community pharmacies, other identified sources of drugs used by the respondents for self-medication were friends and relatives and left-over's from previous prescriptions. These other sources, apart from licensed pharmacies, could also pose serious risks to the consumer's health.

\section{Limitations of the study}

This study is limited to self-medication practices with antimalarials and antibiotics only. It did not extend to other categories of medications. This limitation, however, does not affect the validity of the results with regard to the parameters assessed.

\section{CONCLUSION}

The study revealed that the prevalence of self-medication with antibiotics and antimalarials, by university students in Southwestern Nigeria is very high. Selfmedication behaviour varied significantly with a number of socio-demographic characteristics. Since some of the drugs used for self-medication were obtained from unapproved sources, there is need for healthcare professionals to enlighten consumers, through public education, on the problems that may arise from inappropriate medication use.

\section{REFERENCES}

1. Jamison AJ, Kielgast PJ, Hoek AJM, Reinstein JA. Responsible Self- Medication. Joint Statement by the International Pharmaceutical Federation and World Self-Medication Industry. 1999; $p$ 16.

2. Afolabi AO. Factors influencing the pattern of selfedication in an adult Nigerian population. Ann Afr Med 2000; 7(3): 120-127.

3. World Health Organization. Global Strategy for Containment of Antimicrobal Resistance: World Health Organization. Communicable Diseases Surveillance and Response (CRS).WHO/CDS/CRS/DRS/2001.2.2001.

4. Fadara JO, Tamuno I. Antibiotic Self-medication among university medical undergraduates in Northern Nigeria. J. Pub Health Epidemiol. 2011; 3(5): 217-220.

5. Aswapokee N, Vaithayapichet S, Heller RF. Pattern of antibiotic use in medical wards of a university hospital, Bankok, Thailand. Rev Infect Dis 1990; 12 (1): 136-141.

6. Okeke NI, Lamikanra A, Edelman R. Socioeconomic and Behavioral Factors Leading to Acquired Bacterial Resistance to Antibiotics in Developing Countries. Emerg Infect Dis 1999; 5(1): 18-27.

7. Erhun WO, Erhun MO. The qualitative impact of broadcasting media advertisement on the perception of medicines in Nigeria. Journal of Consumer Behavoiur 2002; 3(1): 8-19.

8. Nancy $V$, Markm N. Changing Patterns of Pharmaceutical Practice in United States. Soc Sci Med 1997; 44(9): 1285-1290.

9. Hamel MJ, Odhacha A, Roberts JM. Malaria Control in Bungoma District Kenya: a survey of home treatment of children with fever, bed net use and attendance at antenatal clinics. Bulletin of the World Health Organization. 2001:10-23.

10. Vamil AG. Dangers of Self-Medication, 2005 [cited 2006 April 6]. Available from: http://www.dawn.com

11. Brennam G, Troyen A, Leape L, Laird L, Nan M. Incidence of adverse events and negligence in hospitalized patients. Results of the Harvard Medical Practice Study. England Journal of Medicine 1997; (4): 370-376.

12. Johnson J. Level of Knowledge among adolescent girls regarding effect treatment for dysmenorrhea. J Adolescent Health Care 1998; 12 (9): 398-406.

13. Laurice LB. Medication error. An expose of the Problem, 2000 [cited 2001 May 4] http://www.google.com

14. Award A, Eltayeb L, Matowe L, Thalib L. SelfMedication with Antibiotics and Antimalarias in the Community of Khatoum State, Sudan. J Pharm Pharmaceut Sci 2005; 8(2): 326-331.

15. Lois MV. Sex differences in Legal drug use. In: Worthier AL, Smith MC, Eds. Pharmacy Practice, Social Behavioral Aspects, edn 3,

Trop J Pharm Res, August 2012;11 (4):688 
Osemene \& Lamikanra

USA: Williams and Wilkins Publishing; 1989; $p$ 213-217.

16. World Health Organization (WHO). The Role of Pharmacists in Self-care and Self-Medication. Report of the $4^{\text {th }}$ WHO Consultative Group on the role of pharmacist WHO/DAP/98.13.1998

17. Braithwaite A, Pechere JC. Pan-European survey of patients' attitudes to antimicrobial drugs and antibiotics. J Int Med Res 1996; 24(4): 229236.
18. Joint Admission and Matriculation Board (JAMB) Brochure, 2011.Abuja, Nigeria.

19. Soyombo O. Techniques of Data Collection, Questionnaire Design and Administration. In: Abhulimen RA, Chibuike UU, Eds. Research Design and Implementation in Accounting and Finance, edn 1, Nigeria: University of Benin Press and Institute of Chartered Accountants of Nigeria; 2002;53-100. 